\section{The University of the Middle East}

\section{Hala Taweel}

Hala Taweel is president of the Center for Higher Education in the Middle East, Inc., and is a doctoral student in higher education at Boston College. Address: Center for Higher Education in the Middle East, $54 \mathrm{Ca}$ nal Street, Boston, MA 02114. Phone: 617/248-8622. Fax: 617/ 248-8625. E-mail: <University_of_the_Middle_East@msn.com>. Website: <http://www.ume.org>.

G rowing up in the West Bank, I was forever frustrated Tby the politics that inflamed and kept alive tensions between Israelis and my people, the Palestinians. After all, many of the issues seemed of rather limited significance to those of us busily going about our daily lives. Years later and away from the Middle East, I now better understand the circumstances influencing the region's disparate ideologies. I have come to see these issues not simply as ethnic differences based on historical enmity, but instead as the struggle of two communities attempting to come to terms with themselves and their neighbors. Regretably, efforts at reconciliation have to date been unsuccessful as certain actors remain bent on forwarding their own interests at the expense of the common good.

To combat such thinking, a group of fellow Boston-area students and I began working a year ago to create a mechanism for overcoming these real and perceived differences. Dedicated to the notion that shared goals foster empathy, we are now attempting to create a new learning community in the region, a system of institutions that would not only meet the future educational needs of the swelling population, but would also bring the area's ethnic communities together in an effort to forge mutual understanding and cooperation. Our goal is the creation of a series of university campuses known collectively as the University of the Middle East.

Eventually, a broad network of these campuses is planned throughout the Middle East and North Africa. As a cohort of individual but linked campuses, each location will first address the needs of the country in which it is built. As part of a larger parent university system, however, individual institutions will be linked through both scholarly and student exchange, and joint projects between the faculty and student levels. Despite maintaining regional autonomy, the campuses will be overseen by a single board of trustees selected proportionally from each satellite campus. The board will ensure an equitable distribution of funds, define and determine policy issues, and maintain the principles of the university. Once the system has taken root, the University of the Middle East will offer academic tracks similar to those at other world institutions. These will include undergraduate and graduate degrees in the liberal arts, the physical and social sciences, and professional-oriented programs. We intend that the professional programs will address specific local needs such as medicine, civil engineering, and intergroup studies. All degree programs will incorporate special course design and other opportunities for students from different areas to interact. Undergraduates will spend semesters on exchanges at one or more of the other University of the Middle East campuses. Graduate and professional students will attend their program of interest in the country where it is offered, and will fulfill course requirements that train them to address regional issues in their field. Students in all programs will be required to demonstrate facility in a regional language other than their native tongue. The curricular goal of the university system is to produce a new generation of graduates who, in addition to bringing skills to their respective fields, are trained to address the regional and global challenges of the 21 st century.

\section{Our goal is the creation of a series of university campuses known collectively as the University of the Middle East.}

Support for the University of the Middle East has been overwhelming. Educators, business persons, and political actors from the world over have championed our cause, providing the project with a great deal of initial momentum. As a result, we are now proceeding with plans to launch smallscale pilot programs intended to assess the feasibility of our larger initiatives and provide us a with a better sense of the working logistics of university building. These first programs will bring together scholars and students from the Middle East and North Africa to study subjects of mutual interest such as international and community development, organizational management, nongovernmental work, social justice, public health, and regional business strategies. In an ongoing effort to finance our plans, we continue to raise funds energetically. Although past support has been substantial, the future of the University of the Middle East project hinges on significant additional contributions of expertise, and capital. Information contained on our webpage highlights both past commitments and current needs.

That our project still exists at all bodes well for its future success. It also speaks volumes about the accomplishments that can be realized when political, social, and cultural differences are set aside to work toward a common goal. Founded by a group of Palestinian, Israeli, Lebanese, Jordanian, Egyptian, Moroccan, Arab-American, Jewish-American, and American students committed to fostering cooperation by looking past their differences, this project is a first tentative step toward erasing the history of ignorance and hatred in the Middle East by creating a forum in which future generations can share knowledge and common goals. 